\title{
Lycopene has a protective effect on septic shock-induced cardiac injury in rats
}

\author{
Duzen $\mathrm{IV}^{1}$, Oguz $\mathrm{E}^{2}$, Yilmaz R ${ }^{3}$, Taskin $\mathrm{A}^{4}$, Vuruskan $\mathrm{E}^{1}$, Cekici $\mathrm{Y}^{5}$, Bilgel $\mathrm{ZG}^{6}$, Goksuluk $\mathrm{H}^{7}$, \\ Candemir B ${ }^{7}$, Sucu $\mathrm{M}^{1}$
}

Department of Cardiology, Faculty Of Medicine Gaziantep University,Gaziantep,Turkey. vduzen79@yahoo.com.tr

\begin{abstract}
OBJECTIVE: The aim of the present study is to investigate the cardioprotective effect of lycopene, known for its antioxidant and anti-inflammatory effect, in a rat sepsis model induced by lypopolysaccharide (LPS). METHODS: The oxidative stress parameters, antioxidant parameters and cytokine levels with or without lycopene treatment in LPS-induced septic rats as well as in controls were measured in serum and tissue. Histologic examinations of the cardiac tissues were also performed. The Kruskal-Wallis and the Bonferroniadjusted Mann-Whitney $U$ Test was used for analysis. A $p$ value $<0.05$ was considered significant. RESULTS: The data of this study showed that lycopene pretreatment reduced the oxidative stres parametersand, proinflammatory cytokines as well as increased the antoxidant enzyme activities in both serum and cardiac tissues in LPS-induced septic rats.. Moreover, hyperaemia and haemorrhage in the epicardium, myocardium and endocardium were lower in the lycopene pretreated group as compared to the LPS alone group.

CONCLUSION: These results suggest that lycopene could be beneficial for the prevention of cardiac injury caused by sepsis through reducing the cytokine levels and oxidative stress parameters (Tab. 4, Fig. 1, Ref. 35). Text in PDF www.elis.sk.

KEY WORDS: lycopene, sepsis, antioxidant, anti-inflammatory.
\end{abstract}

\section{Introduction}

Sepsis continues to be a major cause of death among hospitalised patients. In the presence of severe sepsis and septic shock, a supportive treatment in addition to causal therapy is mandatory (1). Depending on the extent of the inflammatory response, the clinical presentation of an affected patient may involve multiple organ failure, including that of the heart, lungs and liver, acute kidney injury, coagulopathy and, eventually, death (2). In the course of sepsis, the cardiac dysfunction may manifest as systolic heart failure or diastolic dysfunction (3). Sepsis-induced myocardial injury is caused by various mechanisms, cytokines, prostanoids and nitric oxide (NO). All have been implicated as major potential factors. Lipopolysaccharides (LPS) are extremely strong stimulators of inflammatory reactions, act at very low concentrations,

${ }^{1}$ Department of Cardiology, Faculty Of Medicine Gaziantep University, Gaziantep, Turkey, ${ }^{2}$ Department of Pharmacology, Faculty of Medicine, Medeniyet University, Istanbul, Turkey, ${ }^{3}$ Department of Pathology, Faculty of Veterinary Science, Harran University, Sanliurfa, Turkey, ${ }^{4}$ Department of Biochemistry, Faculty of Health Sciences, Harran University, Sanliurfa, Turkey, ${ }^{5}$ Cardiology Clinic Dr Ersin Arslan Education and Research Hospital.Gaziantep, Turkey, ${ }^{6}$ Cardiology Clinic 25 Aralik State Hospital, Gaziantep, Turkey, and ${ }^{7}$ Department of Cardiology, Faculty of Medicine, Ankara Univeristy, Ankara, Turkey.

Address for correspondence: I.V. Duzen, Gaziantep University Faculty of Medicine, Cardiology Department, 27310 Sehitkamil, Gaziantep, Turkey. and are involved in the pathogenesis of sepsis and septic shock. Interleukin (IL)-1 $\beta$, and tumour necrosis factor (TNF)- $\alpha$ are proinflammatory cytokines that act as potent drivers of septic shock induced by LPS (4).

Lycopene, primarily found in tomatoes and several other fruits and vegetables, has been tested for its beneficial effects owing to its antioxidant and anti-inflammatory effect (5) Recent epidemiological studies show that an increased serum lycopene level is associated with a reduction in cardiovascular diseases. Animal studies have corroborated this finding by demonstrating the beneficial effect of lycopene in experimental models such as myocardial ischemia reperfusion injury and post-myocardial infarction $(6,7)$. However, there is currently no solid evidence for the protective effect of lycopene in sepsis-induced heart injury.

We thought that lycopene may have a cardioprotective function in sepsis due to its antioxidant and anti-inflammatory properties. In order to elucidate the mechanism of its action, we measured the levels of oxidative stress and inflammatory markers, both in serum and heart tissue samples, and examined histopathological changes.

\section{Material and methods}

This study was undertaken according to the recommendations in the Guide for the Care and Use of Laboratory Animals of the National Institutes of Health with approval by the Committee on 
the Ethics of Animal Experiments of the Dollvet-Hadyek Experimental and Clinical Research Center, Sanliurfa.

Rats used for the study were obtained from the Dollvet-Hadyek Experimental and Clinical Research Center, kept in special cages under appropriate nutritional conditions in the Dollvet-Hadyek Experimental Animals Laboratory. Wistar Albino rats of 10-12 weeks of age, weighing 200-250 g, were used for the experiment. The study was conducted in the Dollvet-Hadyek Experimental and Clinical Research Center laboratory. Measurements of biochemical parameters were performed in the biochemistry laboratory of the Harran University Medical Faculty, and pathological examinations were conducted in the pathology department of the Harran University Faculty of Veterinary Medicine.

Study animals were divided into three groups per 7 rats as follows: Group I, Control; Group II, LPS (s.c. $10 \mathrm{mg} / \mathrm{kg}$ ); Group III, lycopene (i.p. $50 \mathrm{mg} / \mathrm{kg}$ ) for 5 days and LPS (s.c. $10 \mathrm{mg} / \mathrm{kg}$ ) thereafter. Twelve hours after LPS administration, the rats were anaesthetized. The heart was removed following blood sampling from the vena cava. Sera were separated after centrifugation of blood samples. Heart tissues and sera were kept at $-80{ }^{\circ} \mathrm{C}$ until the time of biochemical analysis. Serum and tissue levels of IL-1 $\beta$,

Tab. 1. The levels of cytokines and NO in serum for all groups.

\begin{tabular}{lccc}
\hline Group & $\begin{array}{c}\text { TNF } \\
(\mathrm{pg} / \mathrm{mg} \text {-protein) }\end{array}$ & $\begin{array}{c}\text { IL-1 } \\
(\mathrm{pg} / \mathrm{mg} \text {-protein })\end{array}$ & $\begin{array}{c}\text { NO } \\
(\mu \mathrm{M})\end{array}$ \\
\hline Control & $2756.24 \pm 191.60$ & $884.05 \pm 108.04$ & $6.17 \pm 0.82$ \\
LPS & $3790.56 \pm 114.43 \mathrm{a}$ & $1692.84 \pm 196.46 \mathrm{a}$ & $9.37 \pm 1.08 \mathrm{a}$ \\
LPS+lycopene & $2430.17 \pm 269.89 \mathrm{a}, \mathrm{b}$. & $886.79 \pm 70.72 \mathrm{~b}$ & $6.78 \pm 0.75 \mathrm{~b}$ \\
\hline
\end{tabular}

TNF- $\alpha$ - Tumor necrosis factor alfa, IL- 1 - Interleukin $1, \mathrm{NO}$ - nitric oxide. The values are presented as Mean \pm S.D. $a-$ Significant difference from control $(\mathrm{p}<0.05), \mathrm{b}-$ Significant difference from LPS $(\mathrm{p}<0.05)$.

Tab. 2. The level of cytokines and NO in cardiac tissue for all groups.

\begin{tabular}{lccc}
\hline Group & $\begin{array}{c}\text { TNF } \\
(\mathrm{pg} / \mathrm{mg} \text {-protein })\end{array}$ & $\begin{array}{c}\text { IL-1 } \\
(\mathrm{pg} / \text { mg-protein })\end{array}$ & $\begin{array}{c}\text { NO } \\
(\mu \mathrm{M})\end{array}$ \\
\hline Control & $58.06 \pm 13.91$ & $94.35 \pm 13.43$ & $94.35 \pm 13.43$ \\
LPS & $171.37 \pm 56.78 \mathrm{a}$ & $143.36 \pm 38.62 \mathrm{a}$ & $1.54 \pm 0.08 \mathrm{a}$ \\
LPS+lycopene & $138.38 \pm 33.15 \mathrm{~b}$ & $118.45 \pm 8.72 \mathrm{~b}$ & $0.93 \pm 0.01 \mathrm{~b}$ \\
\hline
\end{tabular}

TNF- $\alpha$ - Tumor necrosis factor alfa, IL-1 - Interleukin $1, \mathrm{NO}$ - nitricoxide. The values are presented as Mean \pm S.D. $a-$ Significant difference from control $(\mathrm{p}<0.05), \mathrm{b}-$ Significant difference from LPS $(\mathrm{p}<0.05)$.
TNF- $\alpha$, NO, LOOH and SH were measured using a commercially enzyme-linked immunosorbent assay (ELISA) kit (Ray Biotech Inc., Diaclone, Cayman).

Serum TOS and TAS were determined using a novel automated measurement method (8). Samples obtained from the heart tissue were fixed in a $10 \%$ formaldehyde solution. Following a routine tissue process, $4-\mu$-thick sections were obtained from paraffin-embedded blocks and stained with haematoxylin-eosin (H\&E) stain. Then, tissue sections were examined under a light microscope, and photographs were taken.

\section{Statistical analysis}

The Kruskal-Wallis test was used to compare the groups, and the Bonferroni-adjusted Mann-Whitney U Test was used to compare the two groups for biochemical parameters. Values of less than 0.05 were regarded as statistically significant. The results are given as mean \pm standard deviation (SD) for biochemical measurements.

\section{Results}

Serum cytokine and NO measurements obtained from the control group, LPS group and Lycopene + LPS group are summarised in Table 1 . Serum TNF- $\alpha$ and IL- $1 \beta$ values were significantly higher in the LPS group as compared to the control group, whereas reduced cytokine levels were found in the Lycopene + LPS group, while being significantly lower compared to the LPS group $(\mathrm{p}<$ 0.05). Cardiac tissue measurements were consistent with serum measurements showing a significant increase in cytokine levels in the LPS group versus the control group and a significant reduction in cytokine levels in the Lycopene + LPS group, as compared to the LPS group $(\mathrm{p}<0.05)$ (Tab. 2). Changes in NO levels closely matched those in cytokine levels. While LPS administration resulted in increased NO levels, the lycopene administration was associated with a significant fall in NO levels $(p<0.05)$ in both serum and cardiac tissue samples.

The measurements of serum and cardiac tissue samples showed that $\mathrm{LOOH}$ (indicator of oxidative stress) levels were significantly high and SH levels (indicator of antioxidant capacity) were low in

Tab. 3. The levels of oxidative stress parameters in serum for all groups.

\begin{tabular}{|c|c|c|c|c|}
\hline Group & $\begin{array}{c}\mathrm{LOOH} \\
(\mu \mathrm{mol} / \mathrm{L})\end{array}$ & $\begin{array}{c}\mathrm{SH} \\
(\mu \mathrm{mol} / \mathrm{L})\end{array}$ & $\begin{array}{c}\text { TAS } \\
(\mathrm{mmolTroloxEquiv/L)}\end{array}$ & $\begin{array}{c}\text { TOS } \\
(\mu \mathrm{mol} \mathrm{H} 2 \mathrm{O} 2 \text { Equiv./L) }\end{array}$ \\
\hline Control & $16.39 \pm 0.78$ & $0.43 \pm 0.03$ & $1.57 \pm 0.17$ & $42.71 \pm 3.02$ \\
\hline LPS & $20.52 \pm 2.53 \mathrm{a}$ & $0.32 \pm 0.02 \mathrm{a}$ & $1.45 \pm 0.05$ & $52.99 \pm 5.18 \mathrm{a}$ \\
\hline LPS+lycopene & $15.92 \pm 1.84 \mathrm{~b}$ & $0.47 \pm 0.05 b$ & $1.72 \pm 0.09 b$ & $28.84 \pm 2.85 b$ \\
\hline
\end{tabular}

LOOH - lipidhydroperoxide, SH - total sulfhydryl, TOS - total oxidant status, TAS total antioxidant status. The values are presented as Mean \pm S.D. a - Significant difference from control $(\mathrm{p}<0.05), \mathrm{b}$ - Significant difference from LPS $(\mathrm{p}<0.05)$.

Tab. 4. The levels of oxidative stress parameters in cardiac tissue for all groups.

\begin{tabular}{|c|c|c|c|c|}
\hline Group & $\begin{array}{c}\mathrm{LOOH} \\
(\mu \mathrm{mol} / \mathrm{L})\end{array}$ & $\begin{array}{c}\mathrm{SH} \\
(\mu \mathrm{mol} / \mathrm{L})\end{array}$ & $\begin{array}{c}\text { TAS } \\
(\mathrm{mmolTroloxEquiv/L)}\end{array}$ & $\begin{array}{c}\text { TOS } \\
(\mu \mathrm{mol} \mathrm{H} 2 \mathrm{O} 2 \text { Equiv./L) }\end{array}$ \\
\hline Control & $1.53 \pm 0.23$ & $0.17 \pm 0.01$ & $0.36 \pm 0.07$ & $6.21 \pm 1.03$ \\
\hline LPS & $2.41 \pm 0.24 \mathrm{a}$ & $0.11 \pm 0.0 \mathrm{a}$ & $0.31 \pm 0.03$ & $0.42 \pm 0.04 \mathrm{~b}$ \\
\hline LPS+lycopene & $1.50 \pm 0.24 \mathrm{~b}, \mathrm{a}$ & $0.14 \pm 0.01 \mathrm{~b}$ & $0.42 \pm 0.04 \mathrm{~b}$ & $6.81 \pm 0.89 b$ \\
\hline
\end{tabular}

LOOH - lipidhydroperoxide, SH - total sulfhydryl, TOS - total oxidant status, TAS total antioxidant status. The values are presented as Mean \pm S.D. a - Significant difference from control $(\mathrm{p}<0.05), \mathrm{b}-$ Significant difference from LPS $(\mathrm{p}<0.05)$. 

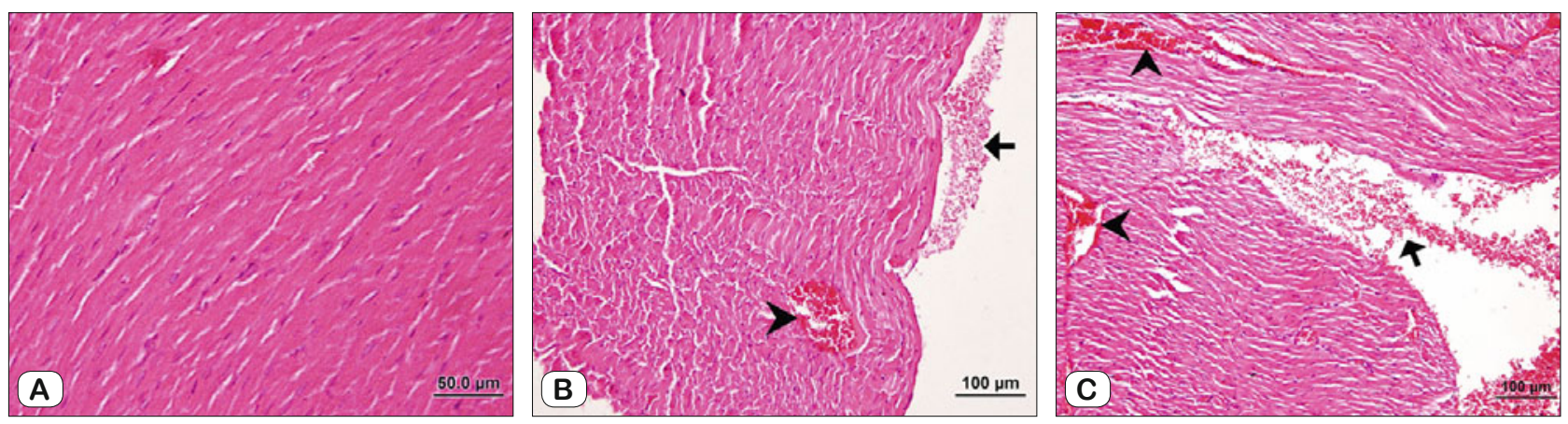

Fig. 1. A. Control group, H\&E, X40. B. LPS+Lycopene group, hyperaemia (arrow head), bleeding (arrow), H\&E, X20. C. LPS group, hyperemia (arrow head), bleeding (arrow), H\&E, X20.

the LPS group $(\mathrm{p}<0.05)$. However, the administration of lycopene had a directly opposite effect on these two parameters.

Based on measurements from serum and tissue samples, TAS was lower in the LPS group compared to lycopene group but the difference was not significant whereas it was significantly higher in the lycopene group versus the control. TOS was significantly higher in the LPS group versus the controls and lower in the lycopene group versus the LPS group $(\mathrm{p}<0.05)$ (Tabs 3 and 4$)$.

\section{Histopathological results}

On histopathological examination, marked hyperaemia and haemorrhage in the epicardium, myocardium and endocardium were observed in both LPS and Lycopene + LPS groups, but not in the controls. However, the severity was higher in LPS group compared with Lycopene+LPS group. In brief, we can state that the severity of hyperaemia and haemorrhage in the LPS group is moderate, while being mild in the Lycopene+LPS group (Fig. 1).

\section{Discussion}

Sepsis is a common condition with a high mortality rate. Antisepsis treatments, though, are not at the desired levels $(9,10)$. As widely observed in patients with severe sepsis, sepsis frequently affects the cardiovascular system and leads to cardiac dysfunction (11). It has been reported that LPS administration induces systemic inflammation similar to many of the initial clinical features of sepsis such as extensive proinflammatory cytokine productions, which leads to multiple organ failure and high mortality rate (12). Therefore, this model is used in many experimental sepsis-induced studies $(13,14)$.

Since sepsis can result in severe organ injury by provoking inflammatory cascades and oxidative stress, we aimed to investigate the possible beneficial effect of lycopene in cardiac damage in sepsis by evaluating the oxidative stress parameters, antioxidant and oxidant status and also proinflammatory cytokine levels in LPS-induced sepsis model, (15). Additionally, the histopathologic examinations were also conducted.

In our study, the increase in ROS generation was reflected in a significant increase in TOS and LOOH levels and significant decrease in SH levels. There was also a decrease in TAS but it was not significant. Oxidative damage associated with the production of excessive amounts of reactive oxygen species (ROS) by activated immune cells is believed to play an integral role in the pathogenesis of sepsis (16). The prominent role of lipid peroxidation in septic shock and secondary organ dysfunction has been reported while the increased occurrence of multiple organ failure occurring in sepsis coincides with increased oxidative stress $(17,18)$.

We demonstrated that lycopene treatment resulted in reduced LOOH levels and TOS, i.e. oxidative stress parameters, whereas SH levels and TAS, i.e. antioxidant indicators, were elevated. Based on this finding, one might deduce that lycopene has a protective effect against LPS-induced oxidative damage via oxidative and antioxidant capacity. Lycopene, an antioxidant carotenoid and the most effective singlet oxygen quencher, has been shown to be a potent antioxidant in both human and animal studies (19-21). In a hypoxia-ischemia study, lycopene improved mitochondrial dysfunction and reduced oxidative stress. It has been suggested that some of the beneficial effects of lycopene in sepsis may take place via its effect on cardiomyocyte mitochondria. It has also been shown in septic patients that lycopene reduces the elevated malondialdehyde (MDA), an end-product formed during oxidative stress, (19). The oxidative stress induced by obstructive jaundice is reduced by lycopene treatment via decreasing MDA and increasing GSH levels in the liver and renal tissues (20). Lycopene $(1 \mathrm{mg} / \mathrm{kg})$ treatment has also a protective effect on renal toxicity induced by carbon tetrachloride administration. It reduces MDA levels and increases antioxidant GSH levels (21).

In our study conducted on LPS-administrated rats, we have seen an increase in both TNF- $\alpha$ and IL- $1 \beta$ levels, i.e. in inflammatory response markers in serum and cardiac tissues as well as that lycopene remarkably attenuated the upregulation of these inflammatory cytokines.

It was reported that TNF- $\alpha$, an inflammatory cytokine, is considered to be an endogenous mediator in LPS-induced shock (22) and that LPS leads to increased TNF- $\alpha$ levels, both in serum and heart tissue (23).

It was suggested that TNF- $\alpha$ and IL1 $-\beta$ act synergistically to cause sepsis-associated myocardial depression in human. (24). Previous studies also revealed that lycopene has anti-inflammatory effects via decreasing cytokine levels in inflammation-related con- 
ditions including sepsis. It has been reported that lycopene showed anti-inflammatory effect on macrophages by reducing proinflammatory cytokine and chemokine expression in LPS-induced sepsis model (25). It was also shown that, lycopene treatment attenuated cardiac dysfunction in diabetic rats via decreasing TNF- $\alpha$ expression $(26,27)$.

Nitric oxide (NO) and other reactive species cause hypotension, excessive vasodilatation and impair oxygen usage in sepsis (28). In our study, we observed an increase in NO levels in LPStreated rats. $\mathrm{NO}$, a potent vasodilator that causes hyperpolarisation of smooth muscle plasma membranes, has a potential role in LPSinduced vascular hyperactivity (29). Peroxynitrite is important in NO-dependent pathogenic mechanisms, as well as in inflammatory conditions such as septic shock, myocardial infarction and chronic inflammatory diseases (30). Endotoxin exposure of human myocardium leads to a depression of cardiac contractility, which is mediated by an enhancement of iNOS activity and release of nitric oxide (NO). It was demonstrated that endotoxin exposure of human myocardium impairs cardiac contractility independently from systemic endotoxin effects. This impairment of myocardial performance appears to be mediated by an enhanced release of NO (31). The data of this study also reveal a significant reduction in NO levels by lycopene both in serum and cardiac tissues in LPSinduced sepsis model. It was reported that oxidative stress and NO deplete lycopene in tissues and human cells and that cardiovascular diseases are accompanied with lycopene depletion (32). A number of studies also show that lycopene suppresses inflammation in several tissues by inhibiting the formation of NO (33). Immunohistochemical examination reveals a significant increase in inducible NO synthase in contrast-induced nephropathy and significant improvements in inflammation, autophagy and apoptosis by administration of lycopene in rats (34).

Epidemiological and clinical studies suggest that dietary antioxidants may reduce the risk of cardiovascular disorders (35). The biochemical and histopathological results of this study underscore the cardioprotective effect of lycopene in an LPS-induced sepsis model in the present study.

\section{Conclusion}

Based on the results of this study, it may be suggested that lycopene supplementation-given alone or in combination with standard therapies, may reduce the oxidative stress and inflammation. As such it may represent a novel adjunct treatment in sepsis and a potential therapeutic candidate for the treatment of cardiac damage in sepsis.

\section{References}

1. Cross AS, Opal S, Cook P, Drabick J, Bhattacharjee A. Development of an anti-core lipopolysaccharide vaccine for the prevention and treatment of sepsis. Vaccine 2004; 22 (7): 812-817.

2. Zarychanski R, Doucette S, Fergusson D et al. Early intravenous unfractionated heparin and mortality in septic shock. Crit Care Med 2008; 36 (11): 2973-2979.
3. Court O, Kumar A, Parrillo JE, Kumar A. Clinical review: Myocardial depression in sepsis and septic shock. Crit Care 2002; 6 (6): 500-508.

4. Buttenschoen K, Radermacher P, Bracht $\mathbf{H}$. Endotoxin elimination in sepsis: physiology and therapeutic application. Langenbecks Arch Surg 2010; 395 (6): 597-605.

5. Yucel Y, Oguz E, Kocarslan S, Tatli O, Gozeneli A, Sezen H, Buyukaslan H, Aktumen A, Ozgonul A, Uzunkoy Aksoy N. The effects of lycopene on methotrexate-induced liver injury in rats. Bratisl Med J 2017:118 (4): 212-6.

6. Müller L, Caris-Veyrat C, Lowe G, Böhm V. Lycopene and Its Antioxidant Role in the Prevention of Cardiovascular Diseases-A Critical Review. Crit Rev Food Sci Nutr 2016; 56 (11): 1868-1879.

7. He Q, Zhou W, Xiong C, Tan G, Chen M. Lycopene attenuates inflammation and apoptosis in post-myocardial infarction remodeling by inhibiting the nuclear factor- $\mathrm{\kappa B}$ signaling pathway. Mol Med Rep 2015; 11 (1): 374-348.

8. Erel O. A novel automated method to measure total antioxidant response against potent free radical reactions. Clin Biochem 2004; 37: 112-119,

9. Plunkett A, Tong J. Sepsis in children. BMJ 2015; 350: h3017.

10. Cohen J, Vincent JL, Adhikari NK et al. Sepsis: A roadmap for future research. Lancet Infect Dis 2015; 15: 581-614.

11. De Geer L, Engvall J, Oscarsson A. Strain echocardiography in septic shock-a comparison with systolic and diastolic function parameters, cardiac biomarkers and outcome. Crit Care 2015; 19: 122.

12. Fink MP. Animal models of sepsis. Virulence 2014; 5 (1): 143-153.

13. Zeng M, Zhang B, Li B, Kan Y, Wang S, Feng W, Zheng X. Adenosine Attenuates LPS-Induced Cardiac Dysfunction by Inhibition of Mitochondrial Function via the ER Pathway. Evid Based Complement Alternat Med 2019 10; 2019: 1832025.

14. Ihan N, Susam S, Gul HF, Bardas R. Which one is more effective for the treatment of rat sepsis model: thalidomide or etanercept? Bratisl Med J 2017; 118 (5): 283-287.

15. Alvarez S, Vico T, Vanasco V. Cardiac dysfunction, mitochondrial architecture, energy production, and inflammatory pathways: Interrelated aspects in endotoxemia and sepsis. Int J Biochem Cell Biol 2016; 81 (Pt B): $307-314$.

16. Goode HF, Webster NR. Free radicals and antioxidants in sepsis. Crit Care Med 1993; 21 (11): 1770-1776.

17. Del Sorbo L, Zhang H. Is there a place for N-acetylcysteine in the treatment of septic shock? Crit Care 2004; 8 (2): 93-95.

18. Tian YF, He CT, Chen YT, Hsieh PS. Lipoic acid suppresses portal endotoxemia-induced steatohepatitis and pancreatic inflammation in rats. World J Gastroenterol 2013; 19: 2761-2771.

19. Yue R, Hu H, Yiu KH et al. Lycopene protectsagainst hypoxia/reoxygenation-induced apoptosis by preventing mitochondrial dysfunction in primary neonatal mouse cardiomyocytes. PLoS One 2012; 7 (11): e50778.

20. Lowe GM, Booth LA, Young AJ, Bilton RF. Lycopene and betacarotene protect against oxidative damage in HT29 cells at low concentrations but rapidly lose this capacity at higher doses. Free Radic Res 1999; 30 (2): 141-151.

21. Moawad KM. Possible prophylactic effects of vitamin E or lycopene treatment on renal toxicity induced by CCLadministration in albino rats. World J Zool 2007; 2 (2): 19-28. 
22. Dinarello CA. Cytokines as endogenous pyrogens. J Infect Dis 1999; 179: 294-304.

23. Vaez H, Rameshrad M, Najafi M, Barar J, Barzegari A, Garjani A. Cardioprotective effect of metformin in lipopolysaccharide-induced sepsis via suppression of toll-like receptor 4 (TLR4) in heart. Eur J Pharmacol 2016; 772: 115-123.

24. Kumar A, Thota V, Dee L, Olson J, Uretz E, Parrillo JE. Tumor necrosis factor alpha and interleukin 1 beta are responsible for in vitro myocardial cell depression induced by human septic shock serum. J Exp Med 1996; 183 (3): 949-958.

25. Marcotorchino J, Romier B, Gouranton E, Riollet C, Gleize B, Malezet-Desmoulins C, Landrier JF. Lycopene attenuates LPS-induced TNF- $\alpha$ secretion in macrophages and inflammatory markers in adipocytes exposed to macrophage-conditioned media. Mol Nutr Food Res 2012; 56 (5): 725-732.

26. Wei Li, Pingping Zhou, Guoguang Wang, Xiaohua Lu, Yuxin Jiang, Xue Zhao. Anti-inflammatory effects of lycopene prevents cardiac dysfunction in streptozotocin-diabetic rats. Int J Clin Exp Med 2016; 9 (5): 8047-8054.

27. Bessler H, Salman H, Bergman M, Alcalay Y, Djaldetti M. In vitro effect of lycopeneon cytokine production by human peripheral blood mononuclear cells. Immunol Invest 2008; 37 (3): 183-190.
28. Prauchner CA. Oxidative stress in sepsis: Pathophysiological implications justifying antioxidant co-therapy. Burns 2017; 43 (3): 471-480.

29. Thiemermann C. The role of the L-arginine: nitric oxide pathway in circulatory shock. Adv Pharmacol 1994; 28: 45-79.

30. Esposito E, Cuzzocrea S. Superoxide, NO, peroxynitrite and PARP in circulatory shock and inflammation. Front Biosci (Landmark Ed) 2009; 14: 263-296.

31. Flesch M, Kilter H, Cremers B et al. Effects of endotoxin on human myocardial contractility. J Am Coll Cardiol 1999; 15 (4): 1062-1070.

32. Petyaev IM. Lycopene Deficiency in Ageing and Cardiovascular Disease. Oxid Med Cell Longev 2016: 3218605.

33. Türk G, Ceribaşi AO, Sakin F, Sönmez M, Ateşşahin A. Antiperoxidative and anti-apoptotic effects of lycopene and ellagic acid on cyclophosphamide-induced testicular lipid peroxidation and apoptosis. Reprod Fertil Dev 2010; 22 (4): 587-596.

34. Buyuklu M, Kandemir FM, Ozkaraca M et al. Benefical effects of lycopene against contrast medium-induced oxidative stress, inflammation, autophagy, and apoptosis in rat kidney. Hum Exp Toxicol 2015; 34 (5): 487-496.

35. Miller NJ, Sampson J, Candeias LP, Bramley PM, Rice-Evans CA. Antioxidant activities of carotenes and xanthophylls. FEBS Lett 1996; 384: $240-246$ 